\title{
Formulation and characterization of sustained release dosage form of moisture sensitive drug
}

\author{
Priya Patel, Abhishek Dave, Amit Vasava, Paresh Patel ${ }^{1}$ \\ Department of Pharmaceutical Sciences, Saurashtra University, Rajkot, 'Shivam Pharmaceutical Studies and Research Center, Valasan, \\ Gujarat, India
}

\begin{abstract}
Objective: The purpose of this study was to prepare sustained release tablet of moisture sensitive drug like Ranitidine Hydrochloride for treatment of gastroesophageal reflux disease along with the improvement of moisture stability to get better therapeutic efficacy. Materials and Methods: Pan coating technique was used for coating of the tablet. Film coating was done using Eudragit RLPO and Eugragit EPO as coating polymer. $3^{2}$ full factorial design was applied for optimization purpose, and 9 runs were conducted. In that Eudragit RLPO and Eudragit EPO taken as an independent variables and moisture gain and Cummulative Drug Release (CDR) were taken as dependent variables. Drug and excipient compatibility was done using differential scanning calorimetry and Fourier transform infrared spectroscopy study. The tablet was evaluated for precompression parameter and all postcompression parameter. Stability study was carried out at room temperature $\left(30^{\circ} \mathrm{C} \pm 2{ }^{\circ} \mathrm{C} / 65 \% \pm 5 \%\right.$ relative humidity). Final formulation was compared with marketed formulation RANTEC 300. Result: Tablets were passing out all precompression parameter along with postcompression parameter. Stability study shows that the parameter such as hardness, friability, and dissolution are in the range. Hence, there is no significant change shown after stability study. Our final formulation was compared with marketed formulation RANTEC 300 and result demonstrates that our final formulation have less moisture gain and give release up to $12 \mathrm{~h}$. Conclusion: The result of present study demonstrates that final formulation has less moisture gain and getting desired CDR for sustained release of drug. On the basis of all study, it was concluded that the tablet was coated by combination of Eudragit RLPO 10\% and Eudragit EPO 10\% give better result. This formation provided promising approach for the drug release up to $12 \mathrm{~h}$ for moisture sensitive drug like ranitidine hydrochloride.
\end{abstract}

Key words: Gastroesophageal reflux disease, moisture stability, pan coating technique, ranitidine hydrochloride, sustained release tablet

\section{INTRODUCTION}

Gastroesophageal reflux disease (GERD) is serious form of gastroesophageal reflux (GER). GER occurs when the lower esophageal sphincter opens spontaneously for varying period or does not close properly, and stomach contains rise into esophagus. GER is also called acid reflux or acid regurgitation because digestive juices called acids rise with the food. The esophagus is a tube that carries food from the mouth to stomach. The lower esophageal sphincter is a ring of muscle at the bottom

\section{Address for correspondence:}

Prof. Priya Patel,

Department of Pharmaceutical Sciences, Saurashtra University,

Rajkot, Gujarat, India.

E-mail: patelpriyav@gmail.com

\begin{tabular}{|l|l|}
\hline \multicolumn{2}{|c|}{ Access this article online } \\
\hline Quick Response Code: & Website: \\
\hline & www.jpionline.org \\
\cline { 2 - 2 } & DOI: \\
\hline$\square$ & $10.4103 / 2230-973 X .153385$ \\
\hline
\end{tabular}

of esophagus that acts like a valve between esophagus and stomach. Persistent reflux that occurs more than twice a week is considered as GERD, and it is eventually lead to more serious health problems. ${ }^{[1]}$

Ranitidine hydrochloride is widely used in the treatment of GERD. Ranitidine hydrochloride is moisture sensitive, so it is necessary to maintain its stability. It is degraded in the presence of moisture because of its hygroscopic nature. Absorb moisture can lead to the catalytic reaction like hydrolysis and oxidation which leads to degradation of the drug and hence decrease in therapeutic efficacy of the drug. ${ }^{[2]}$ Hence, it is necessary to protect ranitidine hydrochloride from moisture to avoid degradation of the drug and to improve the therapeutic efficacy of the drug. ${ }^{[3]}$

Various approaches are used to increase the moisture stability of the drug are as follow:

1. Melt granulation

2. Moisture resistance packaging

3. Coating approach.

Melt granulation technique has the disadvantage like it requires high energy input and meltable binder used in this technique 
should have appropriate melting point in correlation. In this study, coating approach were selected and evaluated for moisture stability. Coating with nonaqueous polymeric coating deals with regulatory restrictions, cumbersome procedures, and pollution. Sugar coating has disadvantage of long processing time and high water influx during coating. ${ }^{[4]}$ Hence, it was decided to select aqueous moisture barrier film coating system for the current study. For coating solution, combination of Eudragit RLPO and Eudragit EPO were selected. ${ }^{[5]}$

\section{MATERIALS AND METHODS}

\section{Materials}

Ranitidine hydrochloride was obtained as a gift sample from Orchev Pharma Pvt. Ltd. Rajkot, India. Microcrystalline cellulose, titanium dioxide, polyvinyl alcohol were obtained as a gift sample from Loba Chemicals, Mumbai, India. Eudragit RLPO and Eudragit EPO were also obtained as a gift sample from Evonik Degussa Industries, Mumbai, India. Glyceryl monostearate was obtained as a gift sample from JRS Pharma, USA.

\section{Methods}

Drug-excipient compatibility studies

Fourier transform infrared spectroscopy study

Drug and excipient compatibilities were analyzed by IR spectral studies. IR spectra of drug, polymer, drug polymer physical mixture and formulation were obtained using Fourier transform infrared spectroscopy (FT-IR) spectrophotometer. 1-2 mg of sample was gently triturated with $\mathrm{KBr}$ powder and compress into disc by applying pressure for $10 \mathrm{~min}$ in a hydraulic press. The disc was placed in the sample holder and scanned from 4000 $\mathrm{cm}^{-1}$ to $400 \mathrm{~cm}^{-1} \cdot{ }^{[6]}$

\section{Differential scanning calorimetry study}

Weigh the sample to the nearest 1-5 mg with the analytical balance. Record the weight. Use forceps to place the sample in the bottom half of an aluminum differential scanning calorimetry pan. Use forceps to place the lid on top of your sample. Place the sample into sample encapsulating press. Align the sample in the encapsulating press, and press down on the handle to seal aluminum pan. Crimp an empty aluminum pan and lid. You are using the empty pan as a reference sample, and scanning speed was $10^{\circ} \mathrm{C} / \mathrm{min}$ over temperature range of $40-250^{\circ} \mathrm{C} .{ }^{[6]}$

\section{Loss on drying studies}

The determination of the amount of moisture or volatile compound adsorbed by the surface of fumed oxides is obtained by drying the sample in an oven for $3 \mathrm{~h}$ at $60^{\circ} \mathrm{C}$.

Place the crucible with tilted lid in the oven at $105^{\circ} \mathrm{C}$ for $2 \mathrm{~h}$. Place the crucible in desiccator and allow cooling for $30 \mathrm{~min}$. Weigh a prepared crucible with lid and record weight (Wtare). Place approx. $1 \mathrm{~g}$ of sample into the crucible and tap carefully, record the weight (Wstart). Place the crucible with lid in drying oven for $3 \mathrm{~h}$. After $3 \mathrm{~h}$ time period, take crucible out of the oven and being careful not to create turbulence. Replace the lid to the closed position. Place the crucible in a desiccator and allow cooling for $30 \mathrm{~min}$. Reweigh the crucible with closed lid and record as (Wdry) and calculate the $\%$ loss on drying by using formula: ${ }^{[7]}$

$\% \mathrm{LOD}=\mathrm{W}$ start $-\mathrm{Wdry} / \mathrm{W}$ start $-\mathrm{Wtare} \times 100$

\section{Moisture uptake study}

Moisture uptake study was carried out at three different level of 22,57 , and $75 \%$ relative humidity (RH). A controlled humidity environment was produced using laboratory desiccators containing a saturated solution of various salts. Potassium acetate, sodium bromide, and sodium chloride were used to provide 22 , 57 , and $75 \% \mathrm{RH}$, respectively, at $25^{\circ} \mathrm{C}$. $\% \mathrm{RH}$ was measured by hygrometer. ${ }^{[8]}$

\section{Preparation of core tablet}

Weigh all the material accurately as per the formula given below in Table 1. Melt the glyceryl nitrate in china dish and allow to liquefy the material. Add accurate amount of drug and mix well. Allow the mixture to cool. Add microcrystalline cellulose and remaining excipient into dish, mix well and prepare lump mass using PVP K-30 as a binder and pass through sieve and allow granules to dry. After drying, again pass through sieve and compress granules to prepare tablets. ${ }^{[9]}$

\section{Optimization of formulation using $3^{2}$ full factorial design}

A $3^{2}$ full factorial design was employed to systemically study the joint influence of the effect of independent variables on dependent variables. Variables are depicted in below Table 2. In this study, 2 factors are evaluated, each at 3 levels, and experimental trials are performed at all 9 possible batches. On the basis of preliminary trial batches Eudragit RLPO $\left(\mathrm{X}_{1}\right)$ and Eudragit $\left(\mathrm{X}_{2}\right)$ were selected as independent variables and moisture gain (Y1)

\begin{tabular}{|c|c|c|c|c|c|c|c|c|c|}
\hline Batch & F1 & F2 & F3 & F4 & F5 & F6 & F7 & F8 & F9 \\
\hline Ranitidine hydrochloride & 300 & 300 & 300 & 300 & 300 & 300 & 300 & 300 & 300 \\
\hline GMS & 25 & 25 & 25 & 25 & 25 & 25 & 25 & 25 & 25 \\
\hline MCC & 152 & 152 & 152 & 152 & 152 & 152 & 152 & 152 & 152 \\
\hline Aerosil & 8 & 8 & 8 & 8 & 8 & 8 & 8 & 8 & 8 \\
\hline Magnesium stearate & 5 & 5 & 5 & 5 & 5 & 5 & 5 & 5 & 5 \\
\hline Talc & 10 & 10 & 10 & 10 & 10 & 10 & 10 & 10 & 10 \\
\hline Eudragit RLPO & 40 & 40 & 40 & 50 & 50 & 50 & 60 & 60 & 60 \\
\hline Eudragit EPO & 30 & 40 & 50 & 30 & 40 & 50 & 30 & 40 & 50 \\
\hline
\end{tabular}

GMS: Glyceryl monostearate, MCC: Microcrystalline cellulose 
and Cummulative Drug Release (CDR) (Y2) were selected as dependent variables. ${ }^{[9]} 3^{2}$ full factorial design with coded value given in Table 3 for coating of core tablet.

\section{EVALUATION PARAMETER}

\section{Precompression parameter}

The powder mixture is evaluated for precompression parameter such as angle of repose, bulk density (BD), tapped density (TD), Carr's index (CI), and Hausner ratio (HR).

\section{Angle of repose}

The angle of repose was determined by funnel method. The accurately weigh granules were taken in funnel. The height of the funnel was adjusted in such a way that the tip of the funnel just touches the heap of the blends. An accurately weighed sample of the powder was allowed to pass through the funnel freely on to a flat surface. The height $(\mathrm{h})$ and radius $(\mathrm{r})$ of the powder cone were measured and the angle of repose $(\theta)$ calculated using formula as follow:

$\theta=\tan ^{-1}(\mathrm{~h} / \mathrm{r})$

\section{Bulk density}

Bulk density is determined by pouring powder into a graduated cylinder via a large funnel and measure the volume and weight.

\section{Tapped density}

A known weight of the powder was transferred to a measuring cylinder, tapped manually 100 times, and the ratio of weight to volume of the powder gives the TD.

\section{Carr's index}

The CI of powder was measured by using below equation:

$\mathrm{CI}=(\mathrm{TD}-\mathrm{BD}) / \mathrm{TD} \times 100$.

\begin{tabular}{lccc} 
Table 2: Variables & and their level in $\mathbf{3}^{\mathbf{2}}$ design \\
\hline Factor & $\begin{array}{c}\text { Lower } \\
\text { level: } \mathbf{- 1}\end{array}$ & $\begin{array}{c}\text { Medium } \\
\text { level: } \mathbf{0}\end{array}$ & $\begin{array}{c}\text { Higher } \\
\text { level: } \mathbf{1}\end{array}$ \\
\hline Eudragit RLPO $\left(\mathrm{X}_{1}\right)$ & 8 & 10 & 12 \\
Eudragit EPO $\left(\mathrm{X}_{2}\right)$ & 6 & 8 & 10 \\
Dependent variables & Moisture gain $\left(\mathrm{Y}_{1}\right)$ & CDR $\left(\mathrm{Y}_{2}\right)$ & \\
\hline CDR: Cumulative drug release & & &
\end{tabular}

Table 3: Formulation as per $3^{2}$ full factorial design with coded value (all value in $\mathrm{mg}$ )

\begin{tabular}{lccccc}
\hline Batch & \multicolumn{2}{c}{ Coded value } & & \multicolumn{2}{c}{ Actual value } \\
\cline { 2 - 3 } \cline { 5 - 5 } & $\mathbf{X}_{\mathbf{1}}$ & $\mathbf{X}_{\mathbf{2}}$ & & $\mathbf{X}_{\mathbf{1}}$ & $\mathbf{X}_{\mathbf{2}}$ \\
\hline F1 & -1 & -1 & & 40 & 30 \\
F2 & -1 & 0 & & 40 & 40 \\
F3 & -1 & 1 & & 40 & 50 \\
F4 & 0 & -1 & & 50 & 30 \\
F5 & 0 & 0 & & 50 & 40 \\
F6 & 0 & 1 & & 50 & 50 \\
F7 & 1 & -1 & & 60 & 30 \\
F8 & 1 & 0 & & 60 & 40 \\
F9 & 1 & 1 & 60 & 50 \\
\hline
\end{tabular}

\section{Hausner ratio}

Tapped and BD were determined and HR was calculated as follow:

$\mathrm{HR}=\mathrm{TD} / \mathrm{BD}$

\section{Postcompression parameter}

Prepared tablet were evaluated for postcompression parameter such as tablet thickness, hardness, diameter, friability, weight variation test, and percentage drug content.

\section{Tablet thickness}

The thickness of the tablets was determined using Vernier caliper. Five tablets were used, and average values were calculated.

\section{Tablet diameter}

The diameter of the tablet was measured using Vernier caliper.

\section{Tablet hardness}

Hardness indicates the ability of the tablet to withstand mechanical shocks while handling. The hardness of the tablets was determined using Monsanto hardness tester. It is expressed in $\mathrm{kg} / \mathrm{cm}^{2}$. Three tablets were randomly picked, and hardness of the tablets was determined.

\section{Friability}

The friability of tablets was determined using Roche friabilator. It is expressed in percentage (\%). Ten tablets were initially weighed and transferred into friabilator. The friabilator was operated at 25 rpm for $4 \mathrm{~min}$. The tablets were weighed again. The \% friability was then calculated by:

$\%$ Friability $=\frac{\text { Initial weight }- \text { Final weight }}{\text { Initial weight }} \times 100$

$\%$ Friability of tablets $<1 \%$ are considered acceptable.

\section{Weight variation test}

To study weight variation 20 tablets of the formulation were weighed using a digital balance and the test was performed according to the official method. Twenty tablets were selected randomly and weighed individually to check for weight variation. Take average weight of 20 tablets. No $>2$ tablet deviate from the average weight.

\section{Drug content}

This test is performed to check the uniformity of amount of active medicament in the whole batch. Totally, 10 tablets were selected randomly, weighed a tritured. A quantity of triturate equivalent to $90 \mathrm{mg}$ of ranitidine hydrochloride was dissolved in $0.1 \mathrm{~N} \mathrm{HCl}$ in $100 \mathrm{ml}$ volumetric flask. The solution formed was suitably diluted to get $10 \mu \mathrm{g} / \mathrm{ml}$, and the absorbance was measured at $325 \mathrm{~nm}$ using $0.1 \mathrm{~N} \mathrm{HCl}$ as a blank. Amount of drug present in one tablet was calculated.

\section{In vitro dissolution study}

The release rate of ranitidine hydrochloride tablet was determined using USP apparatus type 2 (USP rotating paddle method). 
The dissolution test was performed during $900 \mathrm{ml} 0.1 \mathrm{~N} \mathrm{HCl}$ $(\mathrm{pH}-1.2)$ at $37^{\circ} \mathrm{C}$ at $100 \mathrm{rpm} .5$ samples were withdrawn hourly for $2 \mathrm{~h}$ and replaced with fresh medium. After $2 \mathrm{~h}$, dissolution was performed in $900 \mathrm{ml}$ of $\mathrm{pH} 6.8$ phosphate buffer for $12 \mathrm{~h}$. The sample was filtered through Whattman filter paper No. 41. After that, absorbance was taken at $325 \mathrm{~nm}$ by ultraviolet (UV) spectrophotometer using $0.1 \mathrm{~N} \mathrm{HCL}$ as a blank for $2 \mathrm{~h}$ sampling and $12 \mathrm{~h}$ sampling take $6.8 \mathrm{pH}$ buffer as a blank. ${ }^{[10]}$

\section{Moisture uptake study}

Uncoated and coated tablet was taken into 2 different glass containers and spread uniformly in container. The container was placed in constant humidity (75\% RH) and at room temperature. The weight increase due to moisture absorption was measured by taking weight at different intervals such as $1,2,3,4,5,6,7,20,32,44,56,68$, and $92 \mathrm{~h}^{[3]}$

\section{Stability study}

The purpose of stability study is to provide evidence on how quality of the drug substance or a drug product varies with time under the influence of environmental factors such as temperature, humidity, and light. The storage condition used for stability study was room temperature $\left(30^{\circ} \mathrm{C} \pm 2{ }^{\circ} \mathrm{C} / 65 \% \pm 5 \% \mathrm{RH}\right)$. Tablets of optimized formulation were packed in aluminum foil and kept in plastic zip bags for 30 days. After this time period, tablets were analyzed for parameter such as moisture uptake study, weight variation, hardness, friability, and in vitro dissolution. ${ }^{[11,12]}$

\section{Comparison with marketed formulation Moisture uptake study}

Coated and marketed tablet (RANTEC 300) was taken into 2 different glass containers and spread uniformly in container. The container was placed in constant humidity (75\% RH) and at room temperature. The weight increase due to moisture absorption was measured by taking weight at different intervals such as $1,2,3$, $4,5,6,7,20,32,44,56,68$, and 92 h. ${ }^{[7]}$

\section{In vitro dissolution study}

The release rate of Prepared Ranitidine Hydrochloride tablet and marketed tablet (RANTEC 300) was determined using USP apparatus type 2 (USP rotating paddle method). The dissolution test

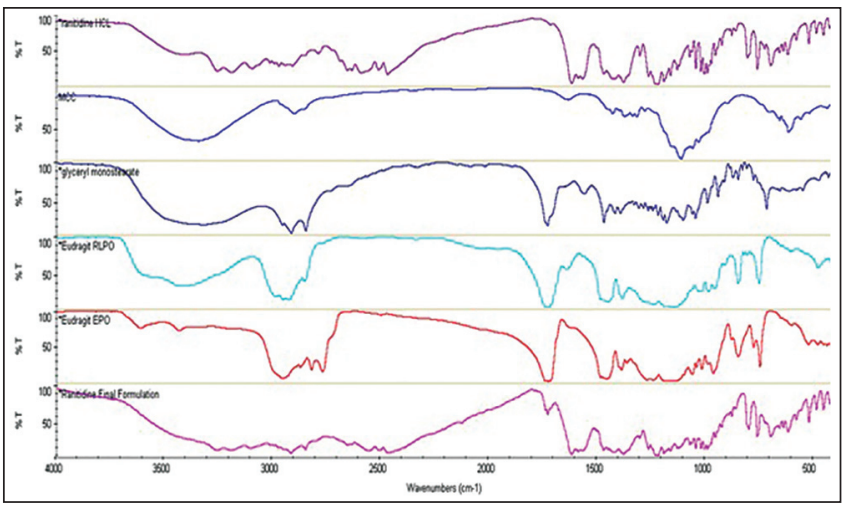

Figure 1: Fourier transform infrared spectroscopy spectra of Ranitidine Hydrochloride, Microcrystalline cellulose, Glyceryl monostearate, Eudragit RLPO, Eudragit EPO and physical mixture was performed during $900 \mathrm{ml} 0.1 \mathrm{~N} \mathrm{HCl}(\mathrm{pH}-1.2)$ at $37^{\circ} \mathrm{C}$ at 100 rpm. 5 samples were withdrawn hourly for $2 \mathrm{~h}$ and replaced with fresh medium. After $2 \mathrm{~h}$, dissolution was performed in $900 \mathrm{ml}$ of $\mathrm{pH}-6.8$ phosphate buffer for $12 \mathrm{~h}$. The sample was filtered through Whattman filter paper No. 41. After that absorbance was taken at $325 \mathrm{~nm}$ by UV spectrophotometer using $0.1 \mathrm{~N} \mathrm{HCL}$ as a blank for $2 \mathrm{~h}$ sampling and $12 \mathrm{~h}$ sampling take $6.8 \mathrm{pH}$ buffer as a blank. ${ }^{[7]}$

\section{RESULT AND DISCUSSION}

\section{Drug-excipient compatibility study \\ Fourier transform infrared spectroscopy study}

The FT-IR spectra of pure drug, excipient, and physical mixture (drug + excipient) are shown in below Figure 1. All principal peak of ranitidine hydrochloride were found in the physical mixture which indicates that there was no interaction between drug and excipient.

\section{Differential scanning calorimetry study}

As shown in Figure 2, the endothermic peak of Ranitidine Hydrochloride was observed at $146.19^{\circ} \mathrm{C}$ and this peak is also observed in the final formulation. It indicates that there was no interaction between drug and excipient.

\section{Loss on drying study}

Not $>0.75 \%$ determined on $1 \mathrm{~g}$ by drying in an oven at $60^{\circ} \mathrm{C}$ at a pressure not exceeding $2.75 \mathrm{kPa}$ for $3 \mathrm{~h}$.

- Wstart $=40.528 \mathrm{mg}$

- $\quad$ Wtare $=39.528$

- $\quad$ Wdry $=40.451$

- $\%$ LOD $=$ Wstart - Wdry/Wstart - Wtare $\times 100$

- $\% \mathrm{LOD}=7.7 \%$.

From the result, we can conclude that the drug can absorb the moisture up to $7.7 \%$ of its weight. Hence, the drug cannot be able to full fill the criteria.

\section{Moisture uptake study}

Figure 3 shows that moisture uptake profile for $1 \mathrm{~g}$ ranitidine hydrochloride at three different levels of RH such as 75, 57, and $22 \%$ RH. The figure indicates that Ranitidine Hydrochloride exposed to high RH, absorbed maximum amount of moisture.

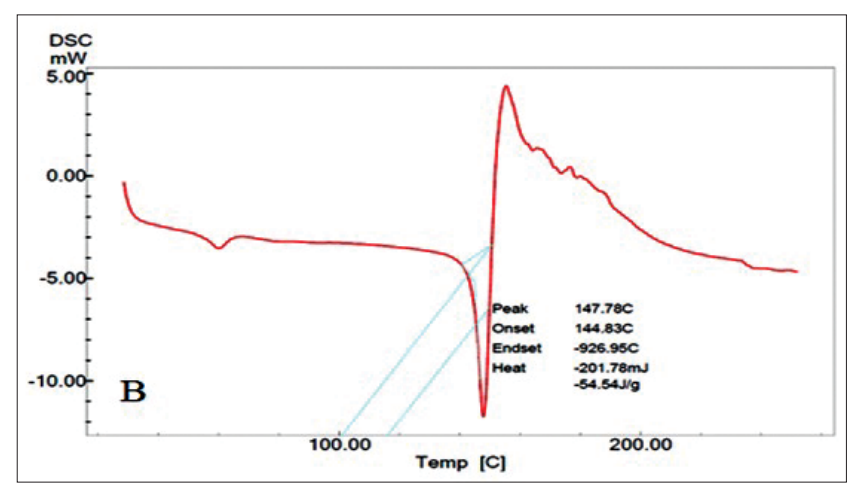

Figure 2: Differential scanning calorimetry thermograph of final formulation Loss on drying study 


\section{OPTIMIZATION OF FORMULATION USING $3^{2}$ FULL FACTORIAL DESIGNS}

The $3^{2}$ full factorial design was used to optimize the amount of Eudragit RLPO and Eudragit EPO for sustained release tablet of ranitidine hydrochloride. The amount of coating material was selected on the basis of the preliminary study. $3^{2}$ full factorial designs was used and prepared total 9 batches (F1 to F9). In those two factors, amount of Eudragit RLPO $\left(\mathrm{X}_{1}\right)$ and the amount of Eudragit EPO $\left(\mathrm{X}_{2}\right)$ were used, and all two factors had three levels $(0,-1$ and 1$)$. Then all batches are evaluated by moisture uptake study by at $75 \% \mathrm{RH}$ and at room temperature and dissolution of all batches are carried out for $12 \mathrm{~h}$ to optimize the best batch.

\section{REGRESSION ANALYSIS}

\section{Effect of independent variable on moisture gain}

Moisture gain $\left(\mathrm{Y}_{1}\right)=20.89-1.83 \mathrm{X}_{1}-3.33 \mathrm{X}_{2}+0.25 \mathrm{X}_{1} \mathrm{X}_{2}$ $+0.17 \mathrm{X}_{1}^{2}-0.33 \mathrm{X}_{2}$.

Below Table 4 depicted full and reduced model for moisture gain. From Table 4, $P$ values are in the range so we can conclude that all the data are significant.

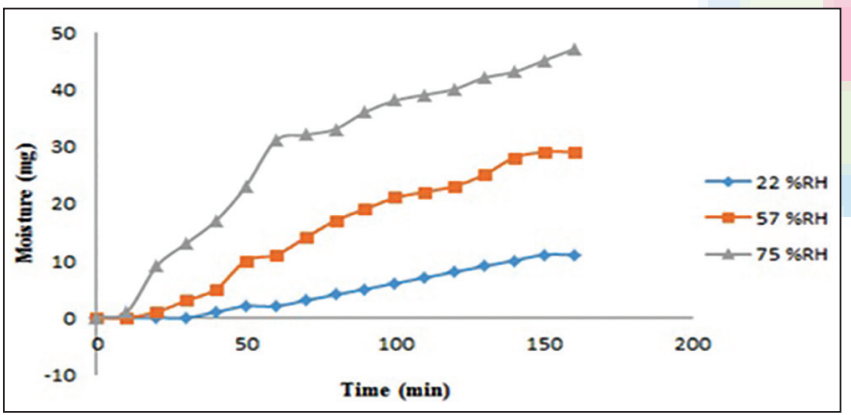

Figure 3: Moisture uptake study of Ranitidine at various \%RH

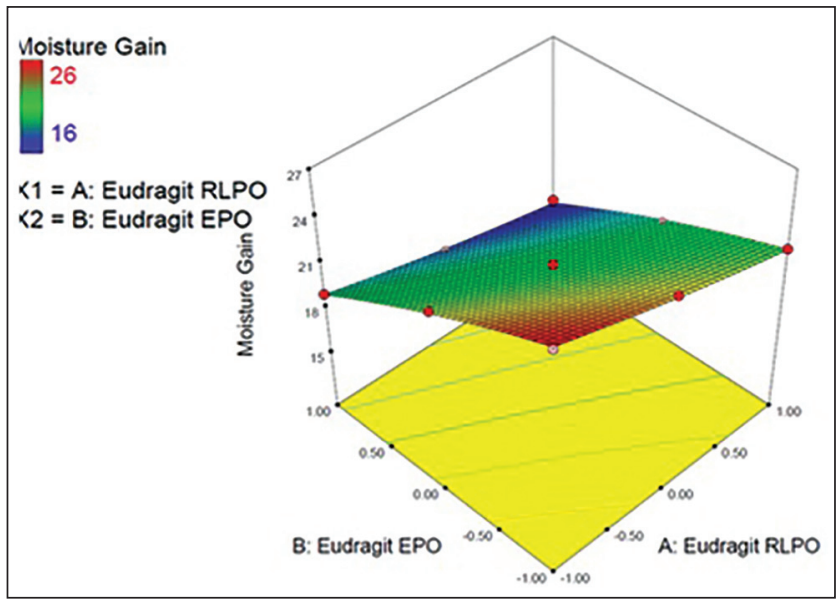

Figure 5: Response surface plot showing effect of variables on moisture gain
In Figure 4, the multiple regression analysis reveals that the increase in the concentration of Eudragit RLPO and Eudragit EPO leads to decrease in moisture gain because the coefficient $b_{1}$ and $b_{2}$ bears a negative sign. When higher percentage of Eudragit RLPO and EudragitEPO is used, the more moisture proof tablet was produced.

In Figure 5, Response surface plot shows that as the concentration of the Eudragit RLPO $\left(\mathrm{X}_{1}\right)$ and Eudragit EPO $\left(\mathrm{X}_{2}\right)$ increases leads to decreases in moisture gain $\left(\mathrm{Y}_{1}\right)$.

\section{Effect of independent variable on Cumulative Drug} Release

$\operatorname{CDR}\left(\mathrm{Y}_{2}\right)=78.98-3.86 \mathrm{X}_{1}+7.58 \mathrm{X}_{2}+0.057 \mathrm{X}_{1} \mathrm{X}_{2}+0.81$ $\mathrm{X}_{1}^{2}-1.07 \mathrm{X}_{2}^{2}$.

Below Table 6 depicted full and reduced model for cummulative drug release. From the table, $P$ values are in the range so we can conclude that all the data are significant.

In Figure 6, the multiple regression analysis reveals that the increase in the concentration of Eudragit RLPO and Eudragit EPO leads to decrease in CDR because the coefficient $\mathrm{b}_{1}$ and $\mathrm{b}_{2}$ bears a negative sign. When higher percentage of Eudragit RLPO and Eudragit EPO is used we get the CDR for a longer time. Hence, we get more sustained release effect of the drug as we increase the concentration of the drug.

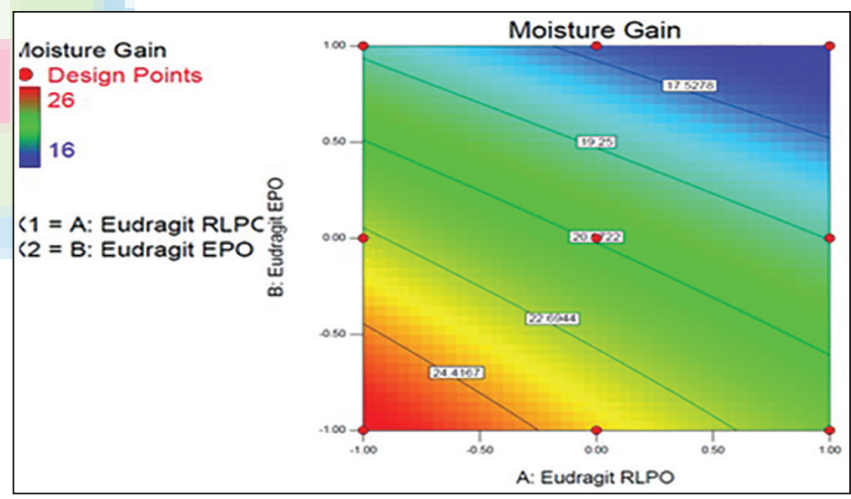

Figure 4: Contour plot showing effect of variables on moisture gain

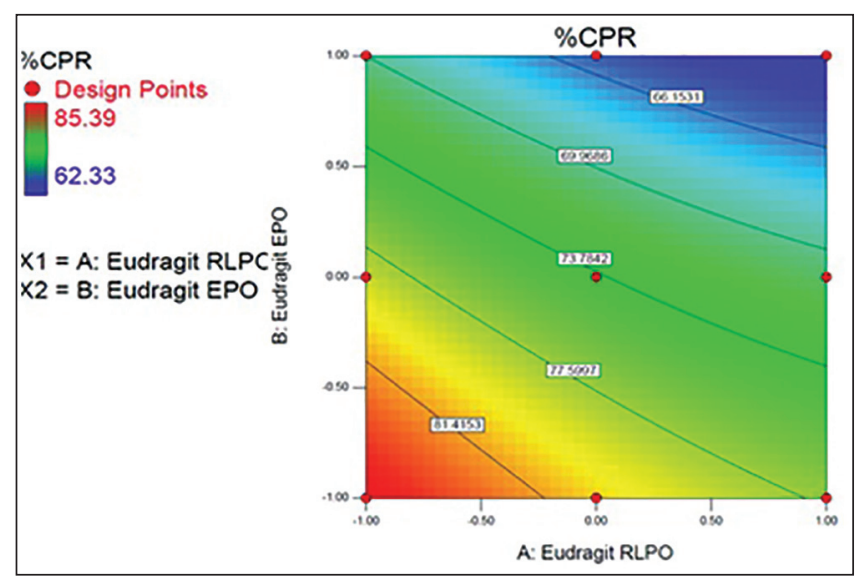

Figure 6: Counter plot showing effect of variables on competent Person's Report 
Table 4: Regression coefficients and polynomial equations for moisture gain

\begin{tabular}{llccccc}
\hline Model & \multicolumn{7}{c}{ Moisture gain $\left(\mathbf{Y}_{1}\right)$} \\
\cline { 2 - 7 } & $\mathbf{b}_{0}$ & $\mathbf{b}_{1}$ & $\mathbf{b}_{2}$ & $\mathbf{b}_{12}$ & $\mathbf{b}_{11}$ & $\mathbf{b}_{22}$ \\
\hline Coefficient value & 20.89 & -1.83 & -3.33 & 0.25 & 0.17 & -0.33 \\
$P$ & & 0.000397 & 0.0006 & 0.1442 & 0.4228 & 0.1611 \\
FM & $Y_{1}=20.89-1.83 X_{1}-3.33 X_{2}+0.25 X_{1} X_{2}+0.17 X_{1}{ }^{2}-0.33 X_{2}$ & & \\
RM & $Y_{1}=20.89-1.83 X_{1}-3.33 X_{2}^{2}+0.17 X_{1}^{2}-0.33 X_{2}$ & & \\
\hline
\end{tabular}

Model validation using ANOVA for both Moisture gain or cumulative drug release data depicted in Tables 5 and 7 respectively. It shows that $\mathrm{Fcal}<\mathrm{Ftab}$ Hence model is validated for both moisturegain as well as Cummulative Drug Release.

In Figure 7, Response surface plot shows that as the concentration of the Eudragit RLPO $\left(\mathrm{X}_{1}\right)$ and Eudragit EPO $\left(\mathrm{X}_{2}\right)$ increases leads to decreases in $\operatorname{CDR}\left(\mathrm{Y}_{2}\right)$.

In Figure 8, overlay plot showing that two different checkpoint batch and Table 8 mention the formula of check point batch was selected for the validation of the design.

The $\%$ relative error for the checkpoint batch was in the range of 5.04-4.54 which is $<8 \%$, so statistically acceptable. It was concluded that the experimental value and predictive value show good agreement between each other.

\section{Evaluation parameter \\ Precompression parameter}

From the precompression parameter of all batches shown in Table 9, angle of repose is within the range and shows that good flow property. $\mathrm{CI}$ and HR also in the range and shows good flow property.

All post compressional parameters like thickness, Diameter, Hardness, Weight variation, Friability and \% Drug content depicted in Table 10. All parameters complies within Range, Drug content complies between $98.28 \%$ to $102.72 \%$.

\section{Postcompression parameter}

In vitro dissolution of $3^{2}$ batches

From Figure 9, dissolution data show that F6 batch gives $86.03 \%$ release of the drug at $12 \mathrm{~h}$ and other batches gives less release as compared to the F6 batch because it contains 10\% Eudragit RLPO and Eudragit EPO 10\% while other batches gives less release of the drugs because of the higher amount of the polymer.

\section{Moisture uptake study}

Moisture uptake study was carried out at $75 \%$ RH for 15 days and result shows in Figure 10 that $\mathrm{F} 7$ batch has less moisture gain because it contains $12 \%$ of Eudragit RLPO and $6 \%$ Eudragit EPO and all other batches show higher moisture gain than F7 batches it contains higher amount of Eudragit RLPO and Eudragit EPO.

\section{Moisture uptake study at room temperature}

Moisture uptake study was carried out at room temperature for 8 days. In Figure 11, that F8 batch has less moisture gain because it contains $12 \%$ of Eudragit RLPO and $10 \%$ Eudragit

\begin{tabular}{|c|c|c|c|c|c|c|}
\hline \multicolumn{7}{|c|}{ Moisture gain } \\
\hline Regression & DF & ss & MS & $\mathbf{F}$ & $\mathbf{R}^{2}$ & F value \\
\hline FM & 5 & 87.36 & 17.47 & 269.57 & 0.9978 & $F_{\mathrm{cal}}=3.84$ \\
\hline RM & 4 & 87.11 & 21.78 & 196.00 & 0.9949 & $F_{\text {tab }}^{\text {cal }}=10.13$ \\
\hline \multicolumn{4}{|l|}{ Error } & \multirow{3}{*}{\multicolumn{3}{|c|}{$\begin{array}{l}F_{\text {cal }}<F_{\text {tab }} \text {, hence model is } \\
\text { validated }\end{array}$}} \\
\hline FM & 3 & 0.19 & 0.065 & & & \\
\hline RM & 4 & 0.44 & 0.11 & & & \\
\hline
\end{tabular}

Table 6: Regression coefficients and polynomial equations for CDR

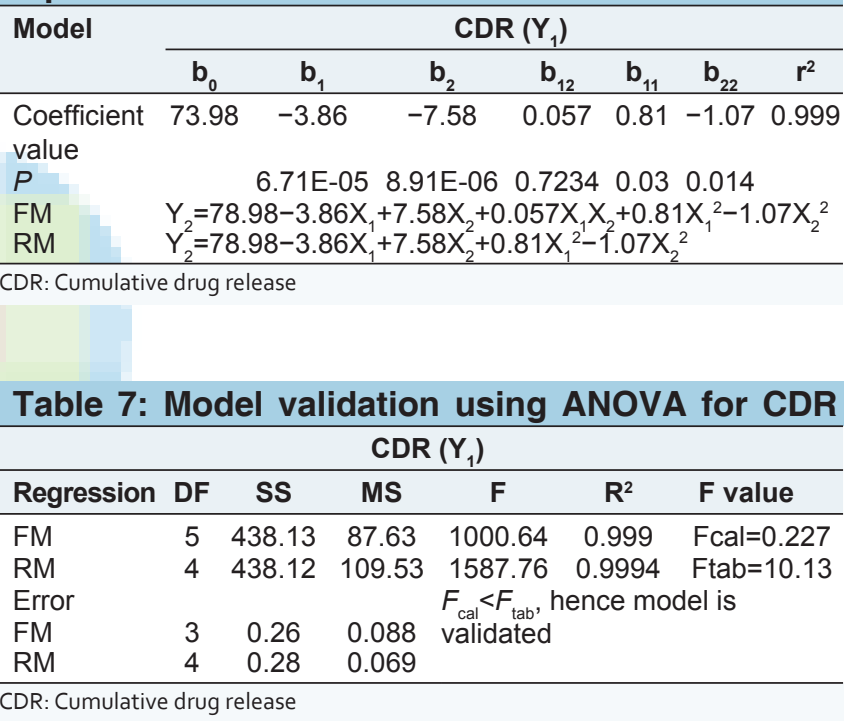

EPO and all other batches show higher moisture gain than F8 batches it contains higher amount of Eudragit RLPO and Eudragit EPO.

\section{Stability study}

Result of stability study shown in Table 11 and Figure 12, it was observed that the prepared sustained release tablet was stable for 1 -month at $\left(30^{\circ} \mathrm{C} \pm 2{ }^{\circ} \mathrm{C} / 65 \% \pm 5 \% \mathrm{RH}\right)$. No significant change was found in the tablet parameter such as weight variation, friability, hardness, drug content, and in vitro dissolution.

\section{Comparison with marketed formulation}

Comparison was carried out with marketed formulation RANTEC 300 and final formulation by dissolution and moisture uptake study. 


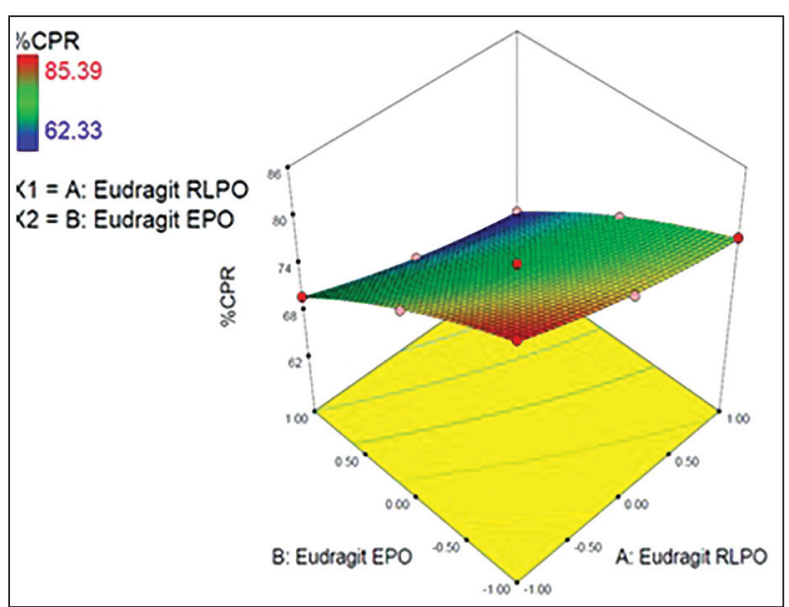

Figure 7: Response surface plot showing effect of variables on Cumulative Drug Release

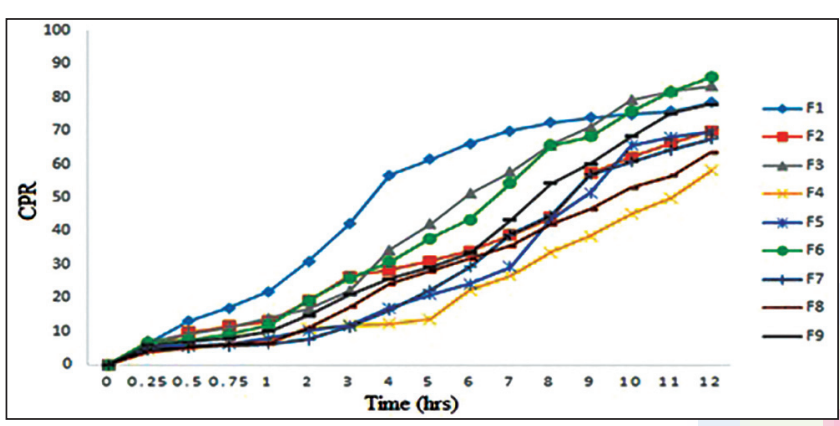

Figure 9: Dissolution profile of all $3^{2}$ design batches

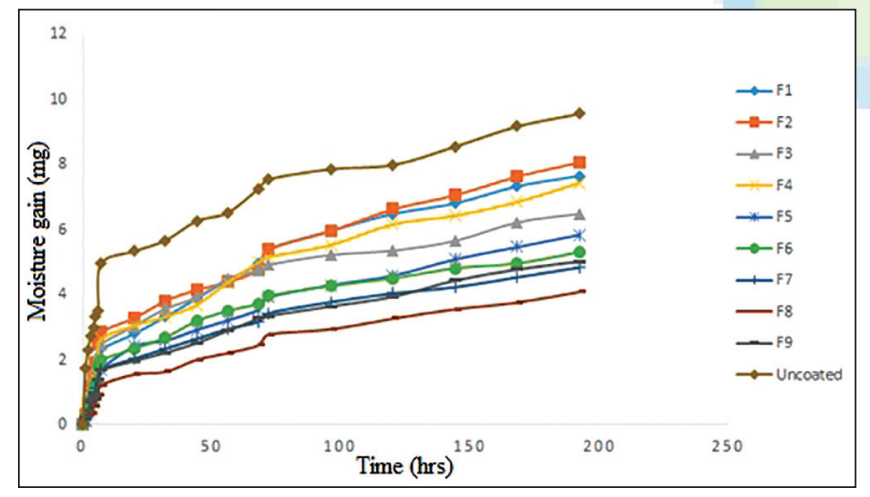

Figure 11: Moisture uptake study of all $3^{2}$ batches at room temperature

\begin{tabular}{|c|c|c|c|c|}
\hline Batch & Polymer & Level & & $\begin{array}{c}\text { Quantity } \\
\text { (mg) }\end{array}$ \\
\hline \multirow[t]{2}{*}{$\mathrm{C} 1$} & Eudragit RLPO & 0.98 & & 51.02 \\
\hline & Eudragit EPO & 0.42 & & 95.23 \\
\hline \multirow[t]{2}{*}{$\mathrm{C} 2$} & Eudragit RLPO & 0.95 & & 52.63 \\
\hline & Eudragit EPO & 0.39 & & 102.56 \\
\hline Batch & Response & $\begin{array}{l}\text { Predicted } \\
\text { value }\end{array}$ & $\begin{array}{c}\text { Observed } \\
\text { value }\end{array}$ & $\%$ error \\
\hline \multirow[t]{2}{*}{ C1 } & Moisture gain & 17.90 & 17.29 & 3.39 \\
\hline & CDR & 67.64 & 70.78 & 4.65 \\
\hline \multirow[t]{2}{*}{ C2 } & Moisture gain & 17.59 & 18.04 & 2.59 \\
\hline & CDR & 66.54 & 70.08 & 5.33 \\
\hline
\end{tabular}

CDR: Cumulative drug release

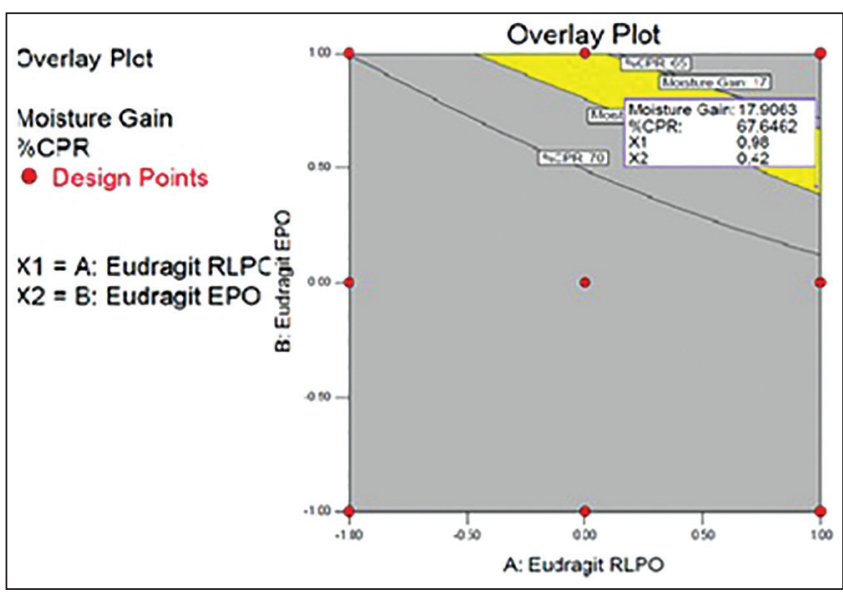

Figure 8: Overlay plot showing combined effects of factors $X_{1}$ and $\mathrm{X}_{2}$ on $\mathrm{Y}_{1}, \mathrm{Y}_{2}$

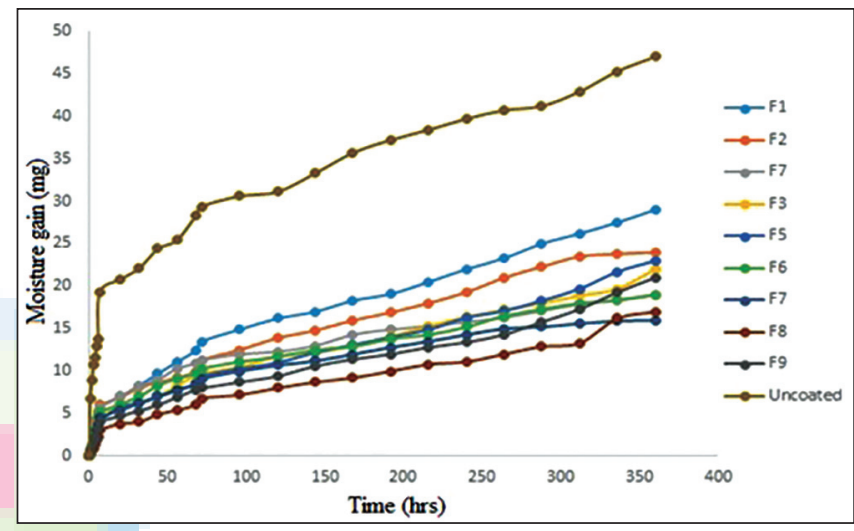

Figure 10: Moisture uptake study of all $3^{2}$ batches at $75 \% \mathrm{RH}$

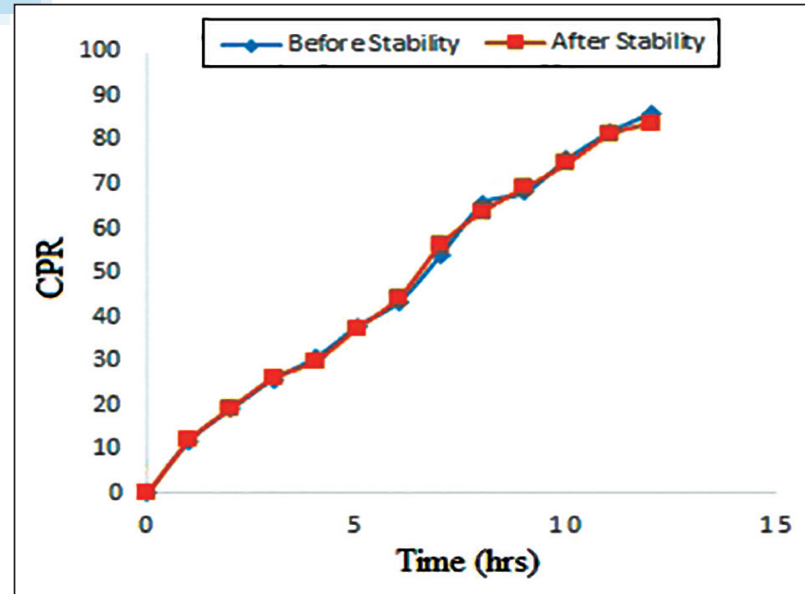

Figure 12: In vitro dissolution of F6 batch before and after stability study

\section{Dissolution study}

Comparison with marketed and final formulation was performed and from result show in Figure 13 that marketed formulation gives release up to $8 \mathrm{~h}$ and our final formulation gives release up to $12 \mathrm{~h}$.

\section{Moisture uptake study}

Moisture uptake study of final and marketed formulation was carried out at $75 \% \mathrm{RH}$ and result shown in Figure 14 that our 


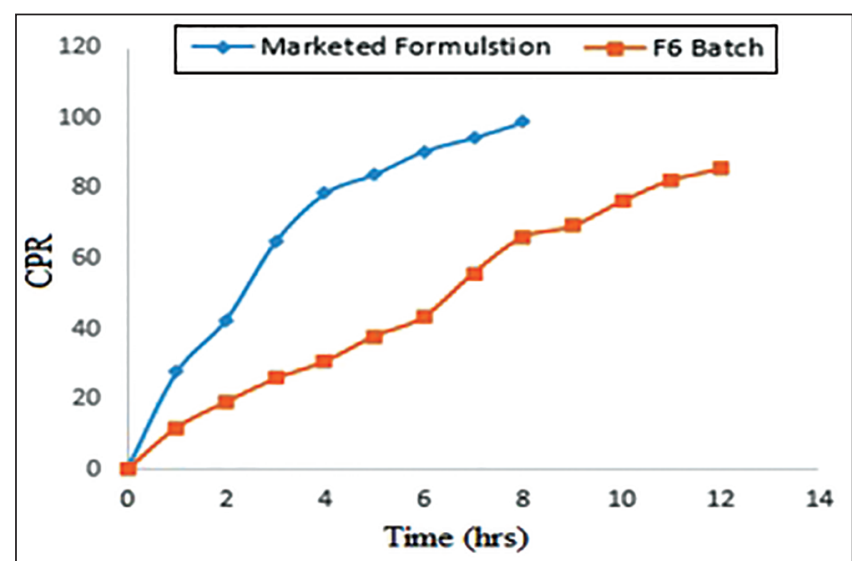

Figure 13: Dissolution study comparison with marketed formulation

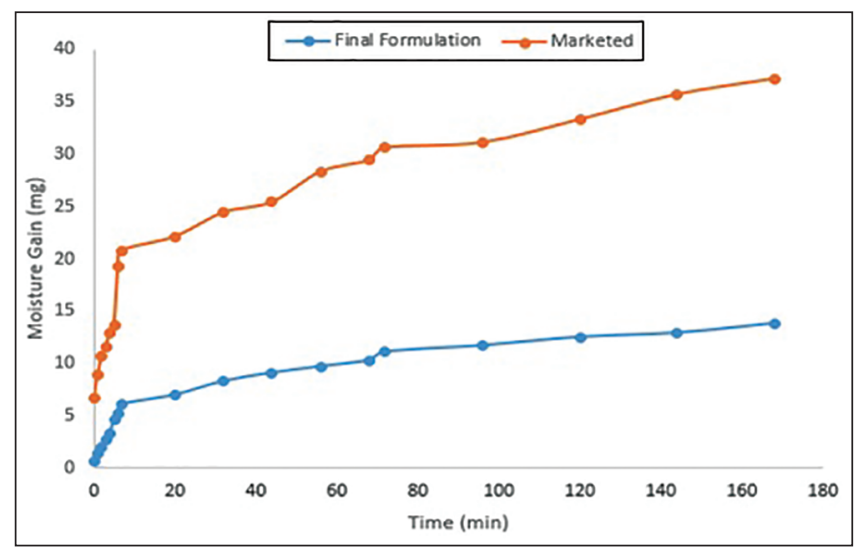

Figure 14: Moisture uptake study comparison with marketed formulation

Table 9: Precompression parameter

\begin{tabular}{|c|c|c|c|c|c|}
\hline Batch & Angle of repose* & Bulk density* $\left(\mathrm{g} / \mathrm{cm}^{3}\right)$ & Tapped density* $\left(\mathbf{g} / \mathrm{cm}^{3}\right)$ & Carr's index & Hausner's ratio \\
\hline F1 & $27.24 \pm 1.07$ & $0.595 \pm 0.04$ & $0.747 \pm 0.08$ & 20.31 & 1.25 \\
\hline F2 & $28.23 \pm 0.92$ & $0.591 \pm 0.02$ & $0.754 \pm 0.04$ & 21.71 & 1.28 \\
\hline F3 & $27.61 \pm 0.72$ & $0.605 \pm 0.05$ & $0.726 \pm 0.02$ & 16.67 & 1.20 \\
\hline F4 & $27.05 \pm 1.01$ & $0.584 \pm 0.02$ & $0.691 \pm 0.07$ & 15.38 & 1.18 \\
\hline F5 & $28.19 \pm 0.85$ & $0.581 \pm 0.01$ & $0.686 \pm 0.06$ & 15.27 & 1.18 \\
\hline F6 & $28.30 \pm 1.20$ & $0.582 \pm 0.06$ & $0.686 \pm 0.03$ & 15.27 & 1.18 \\
\hline F7 & $26.82 \pm 0.75$ & $0.557 \pm 0.03$ & $0.647 \pm 0.08$ & 13.87 & 1.16 \\
\hline F8 & $26.34 \pm 0.46$ & $0.577 \pm 0.04$ & $0.656 \pm 0.05$ & 12.12 & 1.14 \\
\hline F9 & $26.97 \pm 0.77$ & $0.574 \pm 0.05$ & $0.658 \pm 0.06$ & 12.78 & 1.15 \\
\hline
\end{tabular}

*All the values are mean $\pm \mathrm{SD}(n=3)$. SD: Standard deviation

\begin{tabular}{|c|c|c|c|c|c|c|}
\hline Batch & Thickness (mm) & Diameter (mm) & Hardness $\left(\mathrm{kg} / \mathrm{cm}^{2}\right)$ & Weight variation" & Friability (\%) & $\%$ drug content \\
\hline $\mathrm{F} 1$ & $5.24 \pm 0.025$ & $9.11 \pm 0.006$ & $5.27 \pm 0.15$ & $503.5 \pm 1.79$ & 0.261 & 99.43 \\
\hline F2 & $5.30 \pm 0.020$ & $9.12 \pm 0.006$ & $4.77 \pm 0.15$ & $498.4 \pm 2.16$ & 0.306 & 98.85 \\
\hline F3 & $5.19 \pm 0.010$ & $9.11 \pm 0.006$ & $5.87 \pm 0.21$ & $499.6 \pm 2.26$ & 0.351 & 98.28 \\
\hline F4 & $5.20 \pm 0.015$ & $9.12 \pm 0.010$ & $5.10 \pm 0.20$ & $500.5 \pm 2.01$ & 0.305 & 98.47 \\
\hline F5 & $5.23 \pm 0.015$ & $9.12 \pm 0.012$ & $4.83 \pm 0.21$ & $498.2 \pm 2.21$ & 0.220 & 99.81 \\
\hline F6 & $5.20 \pm 0.021$ & $9.13 \pm 0.006$ & $4.97 \pm 0.21$ & $495.8 \pm 2.11$ & 0.395 & 99.04 \\
\hline F7 & $5.21 \pm 0.015$ & $9.12 \pm 0.012$ & $5.30 \pm 0.26$ & $502.6 \pm 1.85$ & 0.351 & 98.85 \\
\hline F8 & $5.32 \pm 0.01$ & $9.12 \pm 0.006$ & $5.07 \pm 0.25$ & $504.3 \pm 2.94$ & 0.305 & 102.30 \\
\hline F9 & $5.36 \pm 0.021$ & $9.12 \pm 0.006$ & $4.57 \pm 0.25$ & $500.7 \pm 2.71$ & 0.219 & 102.72 \\
\hline
\end{tabular}

*All the values are mean $\pm \mathrm{SD}(n=3), " n=20$. SD: Standard deviation

\section{Table 11: Stability study of batch F6}

\begin{tabular}{lcc}
\hline Parameters & \multicolumn{2}{c}{ Batch F6 } \\
\cline { 2 - 3 } & Before stability & After stability \\
\hline Weight variation & $501.12 \pm 1.95$ & $500.12 \pm 0.64$ \\
Friability & 0.223 & 0.308 \\
Hardness & $4.54 \pm 0.13$ & $4.45 \pm 0.11$ \\
Drug content & 98.76 & 97.82 \\
\hline
\end{tabular}

final formulation gain less moisture as compared to marketed formulation.

\section{CONCLUSION}

The result of the present study demonstrates moisture gain was decreased and getting desired CDR for sustained release tablet. Therefore, this formulation provides better treatment for Gastric esophageal Reflux diseases along with the improvement of moisture stability to get better therapeutic efficacy. Thus, on the basis of all the studies, it was concluded that the batch having Eudragit RLPO 10\% and Eudragit 10\% having less than moisture gain and give drug release up to $12 \mathrm{~h}$. Hence, this formulation composition provided promising approach for the drug release up to $12 \mathrm{~h}$ for moisture sensitive drug like ranitidine hydrochloride.

\section{ACKNOWLEDGMENT}

Author wishes to thank Orchev Pharma Pvt. Ltd. Rajkot, India for gift sample of Ranitidine Hydrochloride and Evonik Degussa Industries Mumbai, India for providing gift sample of Eudragit polymer. Author also wishes to thank Head of Department of 
Pharmaceutical Science, Saurashtra University, Rajkot for providing necessary facilities.

\section{REFERENCES}

1. Available from: http://www.en.wikipedia.org/wiki/ gastroesophageal reflux disease. [Last assessed on 2014 Oct 19]

2. British Pharmacopoeia. Properties of Ranitidine Hydrochloride. 2002;1:1481-2.

3. Islam SM, Hossain A, Kabir H, Kabir S, Hossain MK. Study of moisture absorption by ranitidine hydrochloride: Effect of $\% \mathrm{RH}$, excipients, dosage forms and packing materials. Dhaka Univ J Pharm Sci 2008;7:59-64.

4. Bley O, Siepmann J, Bodmeier R. Protection of moisturesensitive drugs with aqueous polymer coatings: Importance of coating and curing conditions. Int J Pharm 2009 13;378:59-65.

5. Thakre S, Bhople A, Deshpande S, Thakre A, Patild S, Shekh T. Optimization and validation of process for formulation and coating of ranitidine. World J Pharm Res 2013;2:382-409.

6. Doshi MM. Controlled release formulations of Ranitidine, Patent No. US5853756 A; 1995.
7. Franz RM. Film coated tablet of ranitidine $\mathrm{HCl}$ Patent No. US4880636 A; 1989.

8. Yadav NR, Ansari IK. Moisture barrier application of selected commercial coating systems. Int J Pharm Res Dev 2013;5:162-70.

9. Khan S, Giradkar P, Yeole P. Formulation design of ranitidine hydrochloride to reduce its moisture absorption characteristics. PDA J Pharm Sci Technol 2009;63:226-33.

10. Tadros MI. Controlled-release effervescent floating matrix tablets of ciprofloxacin hydrochloride: Development, optimization and in vitro-in vivo evaluation in healthy human volunteers. Eur $\mathrm{J}$ Pharm Biopharm 2010;74:332-9.

11. Zahn M. Global stability practices. In: Huynh-Ba K, editor. Handbook of Stability Testing in Pharmaceutical Development. USA: Springer; 2009. p. 90.

12. Nakabayashi K, Shimamoto T, Mima H. Stability of packaged solid dosage forms. II. Shelf-life prediction for packaged sugarcoated tablets liable to moisture and heat damage. Chem Pharm Bull (Tokyo) 1980;28:1099-106.

How to cite this article: Patel P, Dave A, Vasava A, Patel P. Formulation and characterization of sustained release dosage form of moisture sensitive drug. Int J Pharma Investig 2015;5:92-100.

Source of Support: Nil. Conflict of Interest: None declared. 